\title{
Justice within Borders versus Justice without Borders
}

\section{Pradeep Kumar Giri}

Associate Professor, HoD (English Department), Trichandra Multiple Campus, T. U. Kathmandu, Nepal

Only a world without state boundaries could be a just world. It is difficult to defend the view that state boundaries set the limits of distributive justice because it is difficult to say why differences in citizenship should count as morally relevant differences.

-- Charles Beitz

\begin{abstract}
This article intends to study two contrasting notions: borders and beyond the borders in relation to the issue of justice. Formation of a just society is possible with abolition of practice of the concept of partiality or discrimination of any sort. The central claim of this article is that cosmopolitan justice has a reverse relation to nationalist justice; the former is the justice without borders whereas the latter is the justice within borders. Justice presents a conception of just society that humans desire to achieve. Justice can be perceived in two different scenarios: justice in nationalism and justice in cosmopolitanism. Justice in nationalism is justice within borders whereas cosmopolitan justice is Justice without borders. This article discusses how cosmopolitan justice can transcend the borders of time and space of nationalism and how it creates and maintains cosmopolitan egalitarian commitments. It also discusses on how nationalist justice creates borders and considers the compatriots closer, bearing the feeling of special ties, obligations and commitments. Cosmopolitanism - an ideal - emphasizing on humanity and individualism, does not believe in the partial justice; it focuses in equality and impartiality. Justice, in nationalism, is quite differently understood and applied. Nationalism creates borders between the compatriots and non-compatriots and concern and treatment to the compatriots is nearer and dearer to non-compatriots.
\end{abstract}

Keywords—Justice, border, Nationalism, Cosmopolitanism.

\section{COMPARATIVE OVERVIEW OF NATIONALISM AND COSMOPOLITANISM}

The term "cosmopolitanism," derived from Greek word kosmopolites means citizen of the world. From cosmopolitan viewpoint each and every individual, regardless of his/her nationality, is equal and the individual is the ultimate unit of moral concern. Cosmopolitan concept stresses that all human beings, irrespective of their religion, caste, color, culture, birthplace and any other forms of boundaries, belong to a single community. "The term came to indicate someone," according to Daniele Conversi, "who considered the entire humankind as more meaningful than his or her own city, group, religion or state" (34). Defining the concept of cosmopolitanism Brett Bowden argues, "It is reasonable to assume that certain elements of globalization, the ideal of universal human rights, and Nussbaum's twin concepts of world citizenry and cosmopolitan education have further revived cosmopolitanism" (240).

Nationalism, just opposite to cosmopolitanism, creates borders and divides human beings into various nationality groups based on ethnicity, region, religion, culture and so on. Nationalism -- border creator and cosmopolitanism -- borders-eraser, therefore, have reverse relation. Consequently, nationalistic justice and cosmopolitan justice have polar opposite positions and dealings. 
In Samuel Scheffler's view, cosmopolitan justice holds that social boundaries like the boundary of nationality do not impose principled restrictions regarding the scope of conception of justice (112). John Rawls, in his A Theory of Justice, views that justice: "presents a conception of just society that we are to achieve if we can" (346). Principles of justice from cosmopolitan viewpoint erase the boundaries constructed by nationality and citizenship and apply equally to all individuals no matter where they reside and what their nationality is. Nationalism, on the contrary, as a normative idea, stresses on special ties and obligations to the compatriots or fellow-citizen. "Cosmopolitanism," David Miller, in Citizenship and National Identity, says, "respects the conditions that are universally necessary for human beings to lead minimally adequate lives" (174).

Cosmopolitanism, seeking to discover general laws and principles applicable across time and space, would provide a harmonious human unification. The ideal of impartial egalitarianism is central to the cosmopolitan view. Nationalism, just opposite to it, considers ties and commitments of nationality significant. Cosmopolitan view, thus, is directly opposed to the moral partiality inherent to nationalism.

\section{Nationalistic Justice (justice within borders)}

Nationalists believe that they have a special obligation to the compatriots or fellow-citizens. David Miller, in $\mathrm{On}$ Nationality writes: "in acknowledging national identity, I am also acknowledging that I owe special obligation to fellow members of my nation which I do not owe to other human being" (49). The ties of nationality, according to some nationalists cannot be reduced like those of friendship or kinship. But earlier liberal nationalists had realized the significance of common nationality for democratic citizenship.

A sense of national unity emerges and exists as there is a sense of obligation; it exists only between conationals but not between co-nationals and any others. For example, to uplift the color people is an obligation of other color people. Since they are conationals or compatriots or belong to the same racial group; therefore, it becomes their responsibility and obligation to assist the persons who belong to the same nationality group and are lagging behind. This idea clearly presents a portrait of social justice within a country. The notions of obligation to the co-nationals transcend the narrow and intimate boundary of family, kin, and tribe and include the fellow citizen of having the ties of common language, cultural custom and so on. The concept of communal solidarity, thus, has been considered as a notion against liberalism in the matter of solidarity.

What actually the relationship between the members of a nationality highly depends upon is their perception between given relationship. How close the relationship between them is? The answer of this question depends upon the ability to generate associative obligation. It is ultimately a matter of understanding of that relationship rather than a matter of any tangible facts about the relationship. Benedict Anderson has defined the nation as, "an imagined community" (6). In this way the concept of nationality, by creating borders, obstructs in the proper practice of justice in society. A nation, according to Benedict is not like a concrete object but just an imagined idea which neither has a certain definition nor a certain shape.

What can be assumed now is that shared nationality underpins common citizenship and that it is the sort of relationship that can generate associative obligations. Liberal nationalists opine that co-nationals may favor one another only if they are performing their part with respect to cosmopolitan justice. For them national partiality is permissible only if the practice of the partial concern follows and obeys the fundamental duties of justice among all the people. Thus they point out special obligations between co-nationals. Liberal nationalist theorists are ready to accept the concept that national obligations are associative and in the course of maintaining these obligations, obligations of cosmopolitan justice are taken into consideration.

According to David Miller's ideas expressed in Citizenship and National Identity "Communitarian nationalists" (5), unlike the liberal nationalists reject the privileging of cosmopolitan justice to domestic justice. They argue that the analogy between global justice and domestic justice is not justifiable. Kok-Chor Tan aptly says:

While justice may constrain personal pursuits in the domestic setting, global justice cannot constrain national pursuits for the reason that global justice claims cannot be determined independently of national commitments. ... On their view, nationalist commitments properly understood are not subordinated to global 
demands in the way liberal nationalists hope. (187)

The liberal nationalists allow for special obligation only within the term of global justice whereas communitarian nationalists are of the view that the term of global justice should not be impartially defined, as cosmopolitans urge.

The fact what we have to be clear in this connection is that people's moral motivation, often, is limited to those with whom they share a common culture does not mean that it remains limited, and that the scope of their moral concern is fixed and non-extendable. For instance, it is common fact that the moral lesson and education of children begins usually at home; it does not mean that their moral reasoning and scope of moral lesson and education becomes useful for the justice for the society. Kymlicka, in "Two Theories of Justice," rightly puts it, to reject the ideal of justice as impartiality is to propose "an alternative to justice, not an alternative account of justice" (103).

\section{Cosmopolitanism and Cosmopolitan Justice}

As the term "cosmopolitanism" has been used to describe a wide variety of significant views in sociopolitical and moral philosophy, in ancient Greece a cosmopolite would mean a citizen of the world. The concept of cosmopolitanism is that all human beings, regardless of their citizenship, religion, political affiliation and other forms of boundaries, belong to a single community. Cosmopolitanism does not believe in any kind of border, rather it erases or transcends the borders created to narrow down and divide humans giving various names like nationality, culture, religion and so on.

We can identify four overlapping cosmopolitan distinctions in recent writings. The first type refers to cosmopolitanism as an ideal about culture or identity. Cultural cosmopolitans view that membership in a particular community is not constitutive of one's social identity. It stresses that such cultural membership is irrelevant. According to the concept of cultural cosmopolitanism an individual is truly free to borrow from and adapt to a variety of different cultures. Cultural Cosmopolitanism pertains to wide international experience. Equivalent to those two words in English is "Cosmos" and "Polites" having the meanings "world" and "citizen" respectively and was widely used by ancient philosophers such as the "Stoics" and "Cynics" to describe a universal love for humankind as a whole, irrespective of nation.
Modern cosmopolitans express the notion that philosophical cosmopolitans believe that all humans, not only compatriots or fellow citizens, come under the same moral standards. Political and sociological cosmopolitanism stresses that it sees global capital as a possible threat to a nation-state. Cosmopolitanism as a set of moral commitments justifies the kinds of institutions we may impose on individuals and cosmopolitanism as a system of global institutions and organization that represents a world state of some sort. As a moral ideal, cosmopolitanism focuses on equal moral status of individuals.

Moral cosmopolitanism stresses that all human beings stand in a certain moral relation to one another. Explicitly, all individuals are required to respect fellow human being's status as the ultimate unit of moral concern.

Cosmopolitanism as a normative idea considers the individual to be the ultimate unit of moral concern irrespective of nationality and citizenship, ideals of justice transcend nationality and citizenship. Thus, the principles of justice apply equally to all individuals of the world as a whole. Cosmopolitanism about culture considers that social boundaries like the boundary of nationality do not impose "principled restrictions on the scope of an adequate conception of justice" (112) says Samuel Scheffler. It utterly denies the notion that ideals of justice may be fundamentally limited by boundaries like citizenship or nationality. Cosmopolitanism about justice stresses on the irrelevance of boundaries of any kind for the scope of justice considered at the basic level. Defining cultural cosmopolitanism Kok-Chor Tan rightly remarks, "Cosmopolitanism about culture is a thesis about the irrelevance of membership in particular cultures for personal identity formation and individual autonomy" (11).

The idea of justice focuses on the principle of impartial egalitarianism which seems to be opposite to the moral partiality inherent to nationalism. Cosmopolitan justice, by erasing the boundaries created by nationalism, fosters the view that all of humanity belongs to a single moral community. It also accommodates and appreciates nationalist commitments, setting limits for these commitments without denying their moral significance. The idea of Cosmopolitanism, to a great extent, is contrasted with communitarian theories, in particular the ideologies of patriotism and nationalism. Cosmopolitanism may simply refer to more inclusive moral, political or economic relationship between nations or individuals of various different nations. It may or may not entail world government. 
The cosmopolitan idea of justice, from the viewpoint of economic distribution, believes that distributive principles should not be limited by state or national boundaries. Observed from humanitarian perspective the people who are living in absolute poverty should get help by affluent countries. Moral concern of the rich countries is to help all the individuals meet their basic needs. Morally speaking, disregard to the nationality, the affluent countries have, in a sense the obligation of providing humanitarian assistance to the needy individuals. The moral concern should transcend the borders. Not only the moral concern but both humanitarian duties to the foreigners as well as duties of distributive justice are equally needed in some theorists' opinion.

Sometimes it is believed that a global ethic is enough to counter global poverty; an appropriately defined and enforced duty of humanitarianism can meet the subsistence and developmental needs of the poor individuals of the world. But John Rawls entirely rejects the idea of global distributive justice in his book The Law of Peoples. He states that the assistance provided by better-off people to the worst-off individuals is not to reduce inequality as such. He states, "Once the duty of assistance is satisfied and all peoples have a working liberal or descent government, there is no reason to narrow the gap between rich and poor" (114). From his saying it becomes clear that if basic subsistence can be met through the duty of assistance there is no reason for worrying about global institutional inequalities. Though, as Rawls opines, the humanitarian assistance cannot narrow down the gap between poor and rich, mutual assistance among peoples in times of draught and famine is not only needed but it is of great significance if understood from humanitarian perspective.

Cosmopolitans like Singer and Shue have a debate over the ethical starting points of Cosmopolitan justice. The debate between utilitarian and deontological ethical theories is worth-noting in this regard. Utilitarian theory is a consequentialist moral one, and it takes the good of an act or considers a rule to be right or wrong on the basis of the consequences of application of a rule. Defining utilitarianism and deontological theories of cosmopolitanism Tan expresses:

Specifically, act utilitarianism holds that the right act is that which brings about the greatest amount of good for the greatest number of people, and the good to be maximized is understood to be happiness, normally defined in terms of a net gain of pleasure over pain. Deontological theories, on the other hand, while not entirely dismissive of consequences, do not define the right solely in terms of the good. Rather, the rightness or wrongness of an act is to be determined by reference to some defined set of actions or duties, the conformity with which need not necessarily maximize the good. (41)

Some utilitarian cosmopolitan theorists - Singer, Kant - argue that as there is great disparity in wealth and well-being in the population in this world, well-off citizens in rich countries ought to assist the needy and poor of the world up to the point of marginal utility. In this regard Peter Singer, in Philosophy and Public Affairs, argues, "if it is in our power to prevent something bad from happening, without thereby sacrificing anything of comparable moral importance, we ought morally to do it" (407). But Rawls, in his A Theory of Justice, objects to the utilitarian principles of justice. In his view the principles that believe in the fact that our social institutions should aim at maximizing "the net balance of satisfaction" for all individuals in society taken as whole (22) is not plausible.

Tan, however, attempts to show some similarities between utilitarianism and deontological (or rightsbased/action-based) theory of justice. He states, “. . . it is no longer obvious how utilitarianism, conceived as a theory of justice, is distinct from a deontological theory of justice" (45). To make it more clear, he further makes the point, "From the point of view of global justice, then, utilitarianism is distinctive only at the level of (meta) ethical justification it need not necessarily give us a unique set of principles of justice, but only a distinctive way of justifying these principles" (45). Thus, utilitarianism can be considered as a theory of justice which, to a great extent, resembles the features of deontological theories of justice.

Rights-based approach of cosmopolitan justice, unlike the utilitarian approach, would defend some notion of rights. To make the point clear it can be said that a theory of justice which takes rights as indispensable and prominent element can be said to be deontological. As opposed to utilitarian theory, deontological does not take the justness of institutions to be solely dependent if they maximize happiness for society taken as an aggregate whole. Tan points out, "The idea of rights can therefore serve as a suitable starting point for working out a theory of global 
justice" (47). Here, he means to say that if every individual gets equal rights in the matter of access to the resources and if the distribution of resources is justifiable not only in certain groups of community but across the world that can be just in the global level. Therefore, justness in redistribution of resources and equal access in the resources can be considered as a starting point for global justice.

Regarding rights-based approach to global justice, as discussed above, it is one alternative to utilitarian approach. In Tan's view there are two basic rights: the right to security and the right to subsistence. He argues that these rights are fundamental in the sense that the enjoyment of these rights is necessary for the enjoyment of other rights. According to Henry Shue basic rights constitute people's "minimum reasonable demand upon the rest of humanity" (18). One needs to achieve a basic level of subsistence for the enjoyment of security. If one cannot achieve these two rights, to achieve and realize other rights is hardly possible.

As rights and duty are interrelated notions rightbased and duty-based approaches are closely related and need a comparative study and analysis in relation to distributive justice. A duty-based approach, regarding global distributive justice, will press the conceived moral agents regarding the importance of fostering and establishing the appropriate global institutional scheme to allocate and specify the duties of justice to the poor. In this connection it will not be wrong to say that advocates of rights have to be aware that there are important practical steps that need to be taken in the course of facilitating the performance of duties corresponding to the right. Rights generate corresponding obligations including the immediate obligations for the establishment of some means by which these obligations can be assigned and enforced in the real sense. If understood from deontological perspective, rights and duties can be understood as two sides of a sheet of paper. Both offer different ways of presenting and explaining our understanding of justice. For cosmopolitan justice, rightbased and duty-based approaches of assistance to the needy do not offer different conceptual groundings but these are corresponding and closely related.

Concerning the cosmopolitan justice, especially about providing the assistance to the poor and needy by rich people of affluent countries, as basic rights and duties, another significant concept to be discussed is distributive "quality." As discussed earlier, as there are great inequalities between people, the basic rights of the worst-off cannot be fully met due to very many reasons. It is, in most of the cases, because of a mal-distribution of the resources many people live without adequate nourishment, clothing, housing and healthcare but not only because of the shortage of resources globally. In relation to global poverty, there is close link between the concept of poverty and inequality; global poverty can be attributed to pervasive inequality in resource distribution. The unequal distribution of the resource widens the gap between rich and poor. Therefore "distributive justice" is of key concern for cosmopolitan justice.

Cosmopolitans like John Rawls have made attempt to show the importance of transcending beyond the borders of the state to include the world as a whole to make the distributive justice in global level. Rawls expresses this idea in this book A Theory of Justice. He opines that principles of justice should apply between individuals across societies and not just within the borders of a single society. Each person has to have equal right; social and economic inequities are to be arranged so that there can be the greatest benefit of the least advantaged and there can be equality of opportunities in the case of offices and positions. Ulrich Beck's ideas on cosmopolitanism deserves to be noted:

The key idea for cosmopolitan Manifesto is that there is a new dialectic of global and local questions which do not fit into national politics. . . But only in a transnational framework can they be properly posed, debated and resolved. For this there has to be a reinvention of politics, a founding and grounding of the new political subject: that is cosmopolitan parties. (29)

In Charles Beitz's view a complete account of justice has to cover two aspects of justice - "political" justice and "economic" justice (269-296). Political justice concerned with protecting the political and civil liberties of people. Economic justice is concerned with the equal distribution of material goods like resources, wealth, and income and so on. In the cosmopolitan view principles of distributive justice ought to apply equally and impartially to all people and ought not to be constrained by the borders of countries. John Rawls's ideas of distributive justice can give a fruitful insight in this consideration.

John Rawls's The Law of Peoples primarily deals on distributive justice in an international context. Here is what Rawls says in his The Law of Peoples: 
Well-ordered peoples have a duty to assist burdened societies. It does not follow, however, that the only way, or the best way, to carry out this duty of assistance is by following a principle of distributive justice to regulate economic and social inequalities among societies. . but adjusting those levels is not the object of the duty of assistance. Only burdened societies need help. (106)

It is extremely important that these two issues obligations of distributive justice and obligations of assistance-- be distinguished. Rawls's difference principle states that an increase in inequality openly offends to justice, unless the transformation through which this inequality was produced also maximized benefit to the worst-off representative individual. There is some ambiguity as to how this principle would be applied in the international context, but one thing is for sure: obligations of distributive justice would involve transfers a couple orders of magnitude larger than obligations of assistance. For example, since very few theorists believe that any existing welfare state has achieved perfect distributive justice those who discuss global distributive justice must be imagining redistribution on a scale much larger than that which goes on within any existing welfare state.

Rawls's critics, however, seem to have much smaller sums in mind. Charles Beitz imagines that a global resource redistribution principle would ensure "economic conditions sufficient to support just social institutions and to protect human rights" (142). Thomas Pogge talks about transferring one per cent of the GDP of rich nations (205). Pogge is not calling for much more than existing international aid targets, and Beitz's resource redistribution principle has objectives that are no more ambitious than those envisioned under Rawls's own "duty of assistance" (Tan 69).

\section{CONCLUSION}

To conclude, justice in nationalism is justice within the borders and justice beyond the borders in cosmopolitan justice. There is partiality in any form of nationality which creates hindrances in the process of exercising the notion of justice. The principle of impartiality is central to the notion of justice. Justice as such, must be neutral or impartial, as far as possible, between competing partial standpoints or claims. Therefore, the terms of justice are to be determined impartially with respect to particular and special demands if the purpose of justice is to evaluate various demands and claims. Contrary to this, the aim of cosmopolitan justice is a matter to provide the assistance by rich people of affluent countries to the poor and needy individuals irrespective of the citizenship, culture, race and so on. For tackling the problem of global poverty and the big gap between the rich and poor persisting in the world, which may be prevailing from the beginning of existence of human society, we need to develop a cosmopolitan conception of global justice. Thus, cosmopolitanism believes in erasing or transcending the borders created by the concept of various types of nationalism.

\section{REFERENCES}

[1] Anderson, Benedict. Imagined Communities. Verso, 1993.

[2] Beck, Ulrich. "The Cosmopolitan Manifesto." New Statesman, 1998, 29.

[3] Beitz, Charles. Political Theories and International Relations. Princeton UP, 1999.

[4] Bowden, Brett. "Nationalism and Cosmopolitanism: Irreconcilable Differences or Possible Bedfellows?" National Identities, 5.3, 2003, pp. 235-249.

[5] Conversi, Daniele. "Cosmopolitanism and Nationalism." Encyclopedia of Nationalism, Eds. Anthena Leoussi and Anthony D Smith. Transaction Books, 2000, pp. 34-39.

[6] Kymlicka, Will. "Two Theories of Justice." Inquiry, 33, 1990, pp. 99-119.

[7] Miller, David. Citizenship and National Identity. Polity Press, 2000.

[8] ---. On Nationality. Oxford UP, 1995.

[9] Pogge, Thomas W. "Cosmopolitanism and Sovereignty." Ethics, 103.1, Polity Press, 1992, pp. 48-49.

[10] Rawls, John. The Law of Peoples. Harvard UP, 1999.

[11] ---. A Theory of Justice. Harvard UP, 1971.

[12] Scheffler, Samuel. Boundaries and Allegiances: Problems of Justice and Responsibility in Liberal Thought. Oxford UP, 2001.

[13] Shue, Henry. Basic Rights: Subsistence, Affluence, and U.S. Foreign Policy. ${ }^{\text {nd }}$ Ed. Princeton UP, 1996.

[14] Singer, Peter. Philosophy and Public Affairs. Cambridge UP, 1972.

[15] Tan, Kok-Chor. Justice without Borders: Cosmopolitanism, Nationalism, and Patriotism. Cambridge UP, 2004. 